\title{
J-SISTEMO E PARENTISMO
}

\author{
J-sistemo Kaj Parentismo \\ Euleax DE LIMA PEREIRA \\ Universidade Federal do Rio Grande do Sul \\ euleaelias@gmail.com \\ https://orcid.org/0000-0003-3433-7800
}

\begin{abstract}
RESUMO: As relações políticas entre gênero e linguagem vêm sendo cada vez mais discutidas nas comunidades linguísticas. Movimentos de reestruturação do uso linguístico têm ocorrido em várias comunidades, com variantes neutras de gênero. Tais movimentos, e suas respectivas comunidades linguísticas, estabelecem desde mudanças perifrásicas até mudanças léxico-morfossintáticas. Também na comunidade esperantófona, em cuja cultura, o Fundamento, obra prescritiva, tem elevada relevância no desenvolvimento da variante padrão adloquial esperantófona. Assim, no interior da comunidade da variante neutra de gênero do Esperanto, vêm sendo discutidas e praticadas variantes conformes ao Fundamento, com participação de membros da Akademio de Esperanto, órgão prescritor da variante padrão adloquial. O presente artigo trata de tais variantes e tem, em seu núcleo, a apresentação feita pela autora no Simpósio de Esperantologia da UFPR em 2019. PALAVRAS-CHAVE: Esperantologia; Linguagem neutra; Fundamento de Esperanto; Sociolinguística.
\end{abstract}

RESUMO: Politikaj rilatoj inter genro kaj lingvajo estas diskutataj pli kaj pli en lingvo-komunumoj. Movadoj por restrukturiĝo de lingvo-uzo estiĝadas en pluraj komunumoj, kun pluraj genre neŭtraj variantoj. Tiaj movadoj, kaj giaj respektivaj lingvo-komunumoj, starigas ekde frazumecaj gis leksik-morfosintaksaj ŝanĝoj. Ankaŭ en Esperantlingva komunumo, en kies kulturo, Fundamento, preskriba verko, havas altan gravon en la disvolviĝo de formala sablona Esperantlingva varianto. Tiele, interne de la Esperantlingva genre neŭtra varianto, oni diskutas kaj praktikas laŭfundamentajn variantojn, kun partopreno de membroj de la Akademio de Esperanto, preskrib-organo por la formala ŝablona varianto. Ĉ́i tiu artikolo pritraktas laŭfundamentan genre neŭtran Esperanton kaj havas, kiel kernon, la prezentajon, faritan de la aŭtorino, dum la Esperantologia Simpozio de la Federacia Universitato de Paranao (UFPR) en 2019. ŜLOSILVORTOJ: Esperantologio; Genre neŭtra varianto; Fundamento de Esperanto; Socilingvistiko. 


\begin{abstract}
Political relationships between gender and language are being more and more discussed in language communities. Movements of linguistic use restructuring are being made in several communities, with gender neutral lects. Such movements, and their respective communities, stablish from periphrasic to lexicological-morphosyntatical changes. In Esperanto community as well, in whose culture, the Fundamento, a prescriptivework, has high significance in the development of Esperanto's non colloquial standard variety. Thus, within Esperanto's gender neutral varity, Fundamento conforming varieties are being discussed and practiced, with participation of members of Akademio de Esperanto, prescriptive body for non colloquial standard variety. This paper treats Fundamento conforming gender neutral Esperanto and has, in its nucleus, the presentation, made by the author, during the Esperantology Symposium of Parana's Federal University (UFPR) in 2019. KEY WORDS: Esperanto Studies; Gender neutral language; Fundamento de Esperanto; Sociolinguistics.
\end{abstract}

\title{
INTRODUÇÃO
}

Pretende-se, com esta apresentação oral, abordar os diversos processos de implementação de uma linguagem neutra quanto ao gênero na variante padrão do Esperanto, bem como discussões acerca dela na comunidade desta variante linguística.

Cumpre observar aqui uma certa distinção entre o gênero como categoria puramente linguística, isto é, gênero gramatical propriamente dito, e categorias linguísticas cuja referência, em terminologia lógica freguiana, é o gênero, como categoria extralinguística. Assim, em línguas como Português, Sânscrito, Hebraico e Alemão, há gênero gramatical, ao passo que em línguas como Esperanto, Tupi Antigo, Inglês e Japonês, não o há.

Em muitas línguas com gênero gramatical, a menção à categoria extralinguística gênero se dá mediante a categoria linguística de gênero gramatical propriamente dito. Desta forma, em tais línguas, uma linguagem neutra quanto ao gênero enquanto categoria extralinguística passa por uma linguagem neutra quanto ao gênero gramatical, o que se exprime por um novo gênero gramatical. Em Esperanto, na ausência de um gênero gramatical, a neutralidade de gênero se dá meramente como neutralidade na referência da linguagem à categoria extralinguística gênero.

O gênero, como categoria extralinguística, é concebido, nas variantes de gênero neutro de línguas, como identidade de gênero, uma vez que as espécies que caem sob estes gêneros são as categorias homem, mulher, etc., categorias estas no consenso dos contemporâneos estudos de gênero, concebidas como identidades, em última instância, 
conforme o conceito de autodeterminação de gênero estabelecido em dentre outras instâncias nos Princípios de Yogyakarta, não remetendo a marcadores biológicos, comportamentais ou sociais, mas meramente identitários a um certo termo da linguagem, o que suscita discussões sobre circularidade lógica, que não serão aqui abordadas, valendo apenas lembrar que a identidade em relação a um termo linguístico é ela mesma extralinguística, a partir da distinção lógica entre uso e menção.

Algo similar a isto, desenvolvi incipientemente com o akademiano $^{l}$ e lógico Marcos Kramer. É também pertinente observar que, não obstante tal consequência desta concepção nominalista de gênero como autoidentidade, as identidades em relação a significantes da linguagem fundam grupos sociais sociolinguísticos dados a partir do uso destes termos para autorreferência autodeterminada individual de seus membros. Assim, a partir da existência de tais grupos sociais, passa a ser factível uma identidade política ligada não mais a termos da linguagem, mas sim a um dado grupo social historicamente determinado.

Além disso, vastamente nas comunidades linguísticas de linguagem neutra, uma considerável parcela concebe expressamente o gênero como identidade. Tal remissão do conceito de gênero ao conceito de identidade, ocorre também na comunidade esperantista de linguagem neutra, valendo uma certa consideração não explicitada suficientemente rigorosamente acerca do caráter homonímico dos morfemas, em Esperanto, que têm dentre suas significações homonímicas possíveis o significado de identidade de gênero, ou, mais precisamente, gênero como identidade.

Em outras palavras, tal homonímia repousa sobre uma distinção de significação quando a linguagem descreve propriedades humanas ou quando a linguagem descreve propriedades de meros seres vivos. Assim, por exemplo, a palavra ino, quando aplicada a seres humanos, refere-se à identidade feminina, já quando aplicada a animais não humanos ou seres vivos no geral, refere-se a um certo sistema reprodutório, que sói ser chamado feminino.

As diferentes posições, no debate interno da comunidade esperantista, acerca desta homonímia são muito incipientes e fogem ao escopo pretendido por esta apresentação, sendo que a homonímia é ela mesma uma posição muito majoritária neste debate. Assim, as análises e propostas abordadas na variante padrão neutra do Esperanto não fazem distinção lexical entre identidades de gênero específicas e sistemas reprodutórios específicos, como em profesorino (professora) versus noktuino (coruja). Isto é de vital importância porque

\footnotetext{
${ }^{1}$ Membro da Academia de Esperanto, órgão prescritor da variante padrão adloquial do Esperanto.
} 
termos como o neologismo iĉo usado frequentemente na variante neutra e na variante padrão neutra são termos homônimos, como em profesoriĉo (professor), significando identidade masculina, versus noktuiĉ (coruja macho), significando sistema reprodutório costumeiramente chamado de masculino.

No entanto, o Plena Ilustrita Vortaro (PIV) (Dicionário Ilustrado Completo), dicionário oficial da variante padrão adloquial do Esperanto, em sua edição de 2020, não elenca tal homonímia nos verbetes referentes aos gêneros, por exemplo, ino, constando apenas a significação de um sistema reprodutório, distintamente do uso linguístico efetivo na variante padrão coloquial. O mesmo se dá no tratamento sobre gênero (concebido em sinonímia com sistema reprodutório) encontrado no clássico manual de gramática Plena Analiza Gramatiko de Esperanto (Gramática Analítica Completa do Esperanto), de Kálman Kalocsay e Gaston Warighien.

Todavia, tal referência a sistemas reprodutórios se dá mediante o termo sekso (sexo), o qual carrega uma homonímia análoga à dos termos etimologicamente correlatos em outras línguas, sendo, em seu uso linguístico, intercambiável com o termo genro (gênero), analogamente ao que historicamente ocorre entre os termos etimologicamente correlatos a sekso e a genro em outras línguas.

No verbete sobre sekso do Plena Ilustrita Vortaro, tal homonímia se expressa, no entanto, como tendo fundamento in re, a partir de uma significação eminentemente reprodutiva. Na medida em que sekso também designa o órgão genital, tomado como símbolo da diferença reprodutiva, ou sexual, a sexualidade, por alusão aos órgãos genitais enquanto zonas erógenas, passa a pertencer ao campo semântico de sekso, havendo assim deslizamento semântico da reprodução para a sexualidade. Além disso, tal verbete elenca a possibilidade de sekso significar gênero gramatical, embora a desaconselha, reconhecendo a intercambialidade no uso linguístico efetivo.

É importante ressalvar que, entre vários akademianoj, membros da Akademio de Esperanto, é comum o uso dos sufixos de gênero quer seja para marcar identidade de gênero concebida não a partir do sistema reprodutivo mas a partir do conceito de autoidentidade acima explicitado, quer seja para, eminentemente em animais não humanos, marcar sistemas reprodutivos, e, analogamente, também em referência a sistemas reprodutivos humanos. Também é comum o uso de sekso para se referir ao gênero tomado como identidade, bem como para se referir ao gênero gramatical, conforme a nomenclatura adotada por Kramer, Kirilo e Wennergren.

Além disso, uma vez que, sob o verbete sekso, se encontra o verbete transseksemo (inclinação transexual) (ausente no uso linguístico efetivo majoritário do Esperanto), 
conotando a identidade de gênero definida a partir do sistema reprodutivo e de um desejo de pertencimento ao mesmo. Isto se dá a partir do deslizamento semântico de sekso como sistema reprodutivo para sekso como conjunto de organismos possuidores de tal sistema reprodutivo, possibilitando o desejo de pertencimento a sekso significar o desejo de pertencimento ao conjunto de organismos portadores de um dado sekso.

Todavia, esta distinção não será aqui abordada porque a distinção entre o "J-sistemo" e o "parentismo" é uma distinção que remete sobretudo a outra discussão, isto é, a saber, a de que A) as raízes tradicionalmente não neutras do Esperanto devem não ter sua significação não neutra alterada, o que é consenso, acarretando necessidade de substituição deste léxico por um novo léxico, e de B) quais raízes serem adotadas.

$\mathrm{O}$ "J-sistemo" e o "parentismo" se contrapõem à variante padrão do Esperanto e à variante padrão da variante neutra do Esperanto, isto é, à linguagem neutra tradicional no Esperanto.

À variante padrão do Esperanto, porque concebem uma linguagem neutra, e, justamente, em fazendo isso, vêem como problemática a assunção de raízes não neutras, enquanto não neutras, sobretudo as que marcam identidades masculinas, como raízes, a partir das quais, derivam-se palavras de significação de identidades não masculinas. Aqui vale lembrar que para raízes que remetem a animais não humanos, não há assimetria quanto aos morfemas que se referem a sistemas reprodutórios, uma vez que tal sistema é binário, e não unário, incluindo o prefixo vir-. Portanto, tais raízes podem ser, de fato, ditas neutras quanto ao gênero.

Todavia, conforme KALOCSAY e WARIGHIEN (1985), o uso do prefixo virpara marcar o sistema reprodutório historicamente designado masculino resulta de um deslizamento semântico do significado da palavra viro (homem), em que a referência ao gênero masculino como categoria extralinguística, sendo concebida como significando sistema reprodutório, passa não mais a ser marcada negativamente, mas antes positivamente, de modo que, enquanto prefixo, vir- não mais denota viro (homem), mas antes um animal de sistema reprodutório historicamente chamado de macho, como um conceito que engloba o gênero masculino concebido como reprodutório analogamente a sistemas reprodutivos homólogos em outras espécies.

Além disso, conforme KALOCSAY e WARIGHIEN (1985), é possível omitir a referência a gênero, concebido enquanto reprodutório, marcada positivamente pelo prefixo vir-, de modo a que, também no caso de animais não humanos, tal marca se dê negativa e não positivamente. 
À linguagem neutra tradicional, porque concebem inadequada: ou bem, A) a ressignificação das raízes não neutras como se neutras o fossem, violando o Fundamento como norma vigente da variante padrão do Esperanto, e causando ruptura não explícita, porque não perceptível mediante mero uso linguístico, na inteligibilidade intersubjetiva mínima das raízes; ou bem B) a ressignificação do prefixo, violando o Fundamento como norma vigente da variante padrão do Esperanto, e causando ruptura não explícita na inteligibilidade intersubjetiva mínima; ou bem C) o uso de um novo prefixo, go-, para derivar palavras neutras a partir de raízes não neutras, violando o princípio de simetria na ordem derivacional dentre os gêneros caro ao próprio projeto da linguagem neutra.

O J-sistemo surge, em 16 de outubro de 2014, com a publicação na revista Lingva $K_{r i t i k o}$, de um artigo de Marcos Kramer, intitulado Esperanto kaj sekso (Esperanto e sexo). Neste artigo, Marcos Kramer examina as categorias gramaticais de significação do gênero em Esperanto, sincronicamente, na origem do idioma, bem como diacronicamente, à luz do que examina uma série de propostas lexicais da linguagem neutra padrão em Esperanto, a qual, até então, em sua esmagadora maioria, não se dava na variante neutra da variante padrão, isto é, na linguagem neutra consoante o Fundamento de Esperanto, tampouco incluía propostas para novas raízes neutras, substituintes. Posteriormente, em 31 de outubro de 2015, o, também akademiano, Kiril Brosch, publica artigo, também na Lingva Kritiko, em que adere, a partir da escola jurídica de interpretação do Fundamento, à posição krameriana da necessidade de novas raízes, efetivamente neutras.

Todavia, Kirilo Brosch discorda, neste artigo, com o artigo de Kramer, em relação ao pronome neutro utilizado e em relação a quais raízes serem utilizadas. Marcos Kramer advoga, em seu artigo Esperanto kaj sekso, pelo uso do pronome ri, em uso há várias décadas e o majoritário na variante neutra tradicional ou padrão do Esperanto, o que Kirilo advoga como kontraŭfundamenta ${ }^{3}$, advogando pelo retorno ao uso do pronome $\hat{g} i$ como pronome efetivamente neutro. Marcos Kramer, em Esperanto kaj sekso, propõe um algoritmo de produção de raízes não neutras, a partir de raízes neutras, mediante como que um infixo que não exerce efetivamente o papel de infixo no sistema morfológico do Esperanto, uma vez que a raiz base passa a ser esta nova raiz indecomponível como uma palavra derivada por infixação, ou, em outras palavras, tal palavra derivada é lexemizada em raiz. Tal infixo é a semivogal j, donde $J$-sistemo.

\footnotetext{
${ }^{2}$ Revista online de discussão de Esperantologia, redigida por Marcos Kramer e Bertilo Wennergren, ambos membros da Akademio de Esperanto, além de esperantólogos convidados.

${ }^{3}$ Contrário ao Fundamento.
} 
Justamente, tomando tal sistema como um sistema de infixação, Kirilo considera-o contrário ao Fundamento, uma vez que se trata de uma nova estrutura de derivação, injustificável juridicamente a partir do Fundamento. Kirilo então propõe um modelo de produção de novas raízes a partir de diversas outras línguas, como do Inglês, parent, donde o Esperanto parento, donde parentismo. Além disso, em sua análise, neste artigo, Kirilo advoga contra o uso do prefixo vir e a favor do sufixo $i \hat{c}$, estando, portanto, apenas a questão pronominal em aberto, ao que o advogar de Kirilo em favor do pronome $\hat{g} i$ dá nome ao $\hat{\text { gi-parentismo. }}$

O argumento levantado por Kirilo para advogar contra o pronome ri é a formulação do Fundamento, sob algumas traduções, elencar os pronomes como formando uma lista fechada, o que para algumas pessoas interlocutoras é um argumento jurídico um tanto inócuo. Todavia, na medida em que o pronome $r i$ visa significar conceitos relacionados à não binariedade, quando usado por certas pessoas não binárias para serem referidas enquanto não binárias, trata-se de um novo conceito. Portanto, de acordo com a Declaração de Boulogne sûr Mer, declaração de maior valor axiológico no ordenamento jurídico das normas da variante padrão de Esperanto segundo a escola jurídica de interpretação do Fundamento, a criação de um novo pronome passa a ser justificada, para referenciar pessoas não binárias, tão somente.

Porém, costuma-se ultimamente argumentar que, uma vez que ele é legítimo, segundo este raciocínio do parentismo, então ele deve ser legítimo também, no parentismo, como pronome neutro de modo geral.

Também o j-sistemo, sendo justamente, este algoritmo, independe do pronome a ser adotado, podendo ser qualquer um, e não apenas ri. Da mesma forma, o parentismo é, neste artigo de 2015, tal que qualquer uma de suas raízes é proposta como podendo ser adotada independentemente entre si e independentemente de pronome, incluindo a possibilidade de outros pronomes além do pronome $\hat{g} i$. Em 2019, independentemente Kirilo e Kramer propõem um novo sufixo em Esperanto para se referir a pessoas de identidade não binária, -ip, passando tal sufixo a integrar ambas as propostas, como um elemento anexo à discussão que deu origem a ambos os sistemas.

Vale salientar que o importante manual de gramática Plena Manlibro de Esperanta Gramatiko (Manual Completo da Gramática do Esperanto) de Bertilo Wennergren, a obra prescritiva e descritiva da variante padrão do Esperanto mais atualizada, refere-se aos neologismos, ainda não ratificados como pertencentes ao léxico oficial do Esperanto pela Akademio, e usados nas variantes neutras de gênero do Esperanto não mais como evitáveis, e apenas sendo citados como neologismos presentes no efetivo uso linguístico 
da variante padrão coloquial. Uma vez que, em contextos sociais mais formais de uso linguístico, como, por exemplo, na Tutmonda Esperantista Junulara Organizo (TEJO) (Organização da Juventude Esperantista Mundial), tais neologismos como ri e -ip, e uma linguagem neutra de gênero de modo geral, encontram-se presentes, pode-se afirmar que tal uso linguístico tem tido alguma expressão também em um contexto de variações adloquiais, ainda que não a variação adloquial padrão, prescrita formalmente pela Akademio de Esperanto.

\section{RAÍZES NÃO NEUTRAS}

Em seu artigo inaugural, Kramer examina a referência gramatical ao gênero a partir de uma consideração sobre o estatuto de marca positiva ou negativa (nula ou zero) nas oposições linguísticas. Kramer dá o exemplo de palavras, como larĝa e mallarĝa, em que, semanticamente, a primeira marca a largura em geral e a segunda a "largura pequena", de modo a que se possa, pragmaticamente, perguntar "Kiom larĝa?", mas não "Kiom mallarga?".

Assim, o sistema gramatical tradicional, primevo, de menção ao gênero em Esperanto, segundo Kramer, baseia-se em 2 eixos complementares de distinções, a saber, a distinção ajo-ulo (inanimado-animado ou inanimado-pessoa) e as distinções concernentes à categoria extralinguística do gênero. Pelo princípio de economia linguística, deve-se, como diz Kramer, sempre usar a expressão marcada quando se pretende veicular uma ideia cujo conteúdo expressa tal marca, sendo, por conseguinte, seu não uso, sinônimo de se referir a algo que tem, para com a marca, negação categorial, isto é, não pertencer à categoria significada pela marca, ou de o sujeito enunciador desconhecer o pertencimento à categoria significada pela marca.

Desta maneira, o pronome $l i$ distingue-se do pronome $\hat{g} i$, por ter a marca da pessoalidade (uleco), e do pronome $\hat{s} i$, por não ter a marca do gênero feminino, ineco. Todavia, de tal ausência de marca de gênero na variante primeva do Esperanto, não se segue, segundo Kramer, a efetiva neutralidade de tal pronome. Isto, uma vez que a ausência de uma marca de um gênero masculino, e de uma percepção desde a época desta variante inicial do Esperanto da importância de uma linguagem neutra, dado o contexto sócio-histórico da época, final do século XIX e início do XX, ocasiona que, para se referir ao gênero masculino, use-se o pronome $l i$, em uso muito majoritário em relação ao uso neutro de $l i$.

Deste modo, diacronicamente, com o passar do tempo, há um deslizamento semântico do significado efetivo de $l i$, e, portanto, o pronome $l i$ passa a marcar o gênero 
masculino. Isto é patente, sobretudo, a partir das últimas décadas, em que um certo uso de linguagem neutra tem sido comum na variante padrão, porém sem uso de neologismos, como no parentismo ou no $j$-sistemo, uso este que se faz na expressão $l i$ a $\breve{u} \hat{s} i$, pressupondo a marca do masculino no significado de $l i$.

Há que se fazer uma observação de uma recente mudança semântica na variante neutra das línguas a ponto de conceber os pronomes não mais como se referindo a gêneros, mas sim como sendo termos de uso livre por pessoas de todos os gêneros que assim desejarem se exprimir e serem mencionadas mediante o uso de tais pronomes.

Assim, o uso de um pronome se aproxima do conceito de expressão de gênero, que independe do gênero, e apenas se relaciona com ele, na medida em que normas de gênero são aplicadas na interpretação destas expressões. Isto é patente na expressão inglesa "Which are your pronoms?" ou, em Esperanto, "Kiuj estas viaj pronomoj?”, ou, em Português, “Quais são seus pronomes?”, muito em voga.

Tal deslizamento no conceito de pronome também se aproxima do conceito de gênero como autoidentidade, na medida em que é uma identidade em relação a um termo da linguagem concebido puramente enquanto significante. Todavia, em nem todos os modelos de linguagem neutra na variante padrão, esta concepção é adotada, e, esta ausência de marca de gênero nos pronomes é recente, e, portanto, o pronome li é um bom exemplo de deslizamento semântico da marca de gênero.

Assim, da mesma forma, pode haver um deslizamento, para a marca do gênero masculino, também nos outros vocábulos não marcados quanto ao gênero feminino. Em inúmeros vocábulos, a imensa maioria, justamente não há tal deslizamento, e isto se deu sobretudo diacronicamente, na medida em que houve gradativamente conscientização sobre a importância de linguagem, em algum sentido, neutra. Todavia, em cerca de 30 palavras, desde o início, absolutamente houve tal deslizamento semântico, inclusive ratificado pela Akademio de Esperanto, órgão responsável pela determinação da variante padrão do Esperanto, como, por exemplo, no caso da palavra patro, cuja raiz, de fato, marca o gênero masculino. Parte deste deslizamento se deve ao fato do, diacronicamente desenrolado, processo de desuso do prefixo vir para raízes referentes a seres humanos, embora as raízes de parentesco a rigor não o sejam, mas tal desuso ocorreu também quando tais raízes são usadas para se referir a animais não humanos. Assim, diferentemente de como pretende a variante padrão do Esperanto, o pronome li não é neutro, e, efetivamente, marca o gênero masculino, e, também, diferentemente de como pretende a variante neutra padrão do Esperanto, raízes como patro não são neutras, não bastando a adição de um sufixo masculino, a saber, $i \hat{c}$, para que tais raízes não marquem o gênero masculino. 


\section{J-SISTEMO}

Assim, cumpre observarmos como se dá o j-sistemo. Este é o algoritmo. Adicionese "j" imediatamente posteriormente à primeira vogal de cada raiz a que este algoritmo se aplica. Se ela for “i”, então, altere-se-a para "e", adicionado "j”" imediatamente após tal vogal. Se ela for precedida por "ŭ" ou "r", eliminando-o, e se adicione “j”".

Um argumento comum contra tal algoritmo é que ele não é, efetivamente, neutro, na medida em que etimologicamente, mediante ele, as novas raízes provêm de raízes masculinas, não eliminando a assimetria. Outra variação deste tipo de objeção é a de que as novas raízes provêm de raízes não neutras. Todavia, esta objeção justamente ignora que o próprio objetivo do algoritmo é ser aplicado a raízes não neutras, e, portanto, justamente é este o objetivo da aplicação do algoritmo, valendo lembrar que ele não é, a rigor, uma efetiva infixação. Aquela objeção justamente ignora o caráter acidental da marca do masculino. Do ponto de vista do algoritmo, é irrelevante qual a marca de gênero, quer seja a marca masculina a mais comum, quer ela não o seja.

Desta maneira, da primeira regra do algoritmo, seguem-se: pajtro (de patro), ejdzo (de edzo), frajto (de frato), ajvo (de avo), ojnklo (de onklo), kujzo (de kuzo), nejpo (de nepo), nejvo (de nevo), knajbo (de knabo), bujbo (de bubo), rejgo (de rego), dujko (de duko), grajfo (de grafo), bajrono (de barono), mojnaĥ (de monaho), ajbato (de abato), cajro (de caro), kajvaliro (de kavaliro) e dajmo (de damo). Da segunda regra, fejlo (de filo), fejanĉ (de fianĉ), vejdvo (de vidvo), vejro (de viro), sejnjoro (de sinjoro), prejnco (de princo) e gejgolo (de gigolo). Da terceira regra, frajlo (de fraŭlo), majkizo (de markizo) e lojdo (de lordo).

\section{PARENTISMO}

Desde 2015, vem sofrendo periódicas alterações o léxico do parentismo, em que perdura, um já existente anteriormente, até ao $j$-sistemo, modelo de novas raízes, neutras, tem se dado como inúmeras formulações, quer seja lato sensu, como um modelo de criação de novas raízes mediante etimologia a partir de outras línguas, quer seja stricto sensu, como o modelo de Kirilo Robert Brosch.

Contudo, em sentido estrito, recentemente consolidaram-se dois modelos de parentismo, como atesta recente artigo de Kirilo, Kramer, Robin van der Vliet e Luko Cerrante. A saber, o modelo internacional e o modelo facilitador de transição. O modelo internacional foi escolhido por Kirilo, Kramer, Robin e Luko, dentre inúmeras possibilidades de etimologia a partir de expressões de gênero neutro em diversas línguas 
ou de combinações das formas masculina e feminina em diversas línguas, a partir de critérios como possibilidade de reconhecimento internacional, sonoridade apropriada e contribuição à internacionalidade do Esperanto. A partir deste modelo, percebeu-se um traço positivo dele para a transição da variante padrão e da variante neutra padrão para ele, a saber, sua possibilidade de reconhecimento com relação às raízes não indo-europeias do Esperanto.

Todavia, justamente, à luz deste critério, reavaliou-se a possibilidade de facilitação de transição como critério mais fundamental que o critério de contribuição à internacionalidade do Esperanto, a ponto de tal critério ser praticamente abolido, uma vez que apenas uma das 5 raízes não reconhecíveis permanece em tal modelo, sobretudo na medida em que ela permanece por ausência de uma proposta que atenda a todos os outros critérios que não o critério de contribuição à internacionalidade.

\section{INTERNACIECA PARENTISMO}

São as raízes do internacieca parentismo (parentismo internacional): parento (do Inglês e Francês parent e do Espanhol e Português parental) substituindo patro, ếo (do Turco eş) para edzo, sahodo (do Hindi e do Bengali, sahódar / sahódarā e do Indonésio saudara) para frato, anako (do Indonésio anak) para filo, avuo (do Espanhol abuela/abuelo, Português avó/avô, Galego avoa/avó) para avo, çaĉo (do Hindi ĉâca/ĉấi e do Bengali $\hat{c} a \hat{c} a$ ) onklo, kuzeno (do Inglês cousin, do Francês cousin(e), do Alemão Cousin(e), do Italiano cugino/cugina) para kuzo, nepoto (do Ido nepoto, do Latim nepos, do Esperanto nepotismo, do Espanhol nieto/nieta, do Português neto/neta, do Hindi pota/potee, do Bengali nati/natani) para nepo, nievo (do Francês nièce/niveu, do Inglês niece/nephew, do Alemão Nichte/Neffe) para nevo, fianceo (do Francês fiancélfiancée) para fianĉo, viduo (do Latim vidua/viduus, do Catalão vídua/vidu, do Hindi vidhur/vidhava, do Espanhol viuda/viudo, do Inglês widow/widower) para vidvo, adolto/homo substituindo viro, sioro (do Ido sioro, do Francês (mon)sieur, do Inglês sir, do Italiano signore/signora) para sinjoro, neeŝso para fraŭlo, kido (do Inglês kid, do Alemão Kind, do Holandês kid) para knabo, petolinfano para bubo, rojalo (do Inglês e Francês royal, do Esperanto rojalismo) para reĝ, prenso (do Turco prens/prenses e muitas outras línguas de sonoridade similar) para princo, duco (do Inglês duchy/duchess, do Francês duché/duchesse/duc) para duko, markeso (do Espanhol marqués/marquesa, do Português marquês/marquesa) para markizo, komto (do Ido komto, do Francês comte, do Inglês count, do Italiano conte, do Espanhol/Português conde) para grafo, baruno (do Croata barun, Siciliano baruni, Estoniano parun, e muitas outras línguas de sonoridade similar) para barono, abado (do 
Espanhol abad/abadessa, do Português abadelabadessa e muitas outras línguas com sonoridade similar) para abato, monho (do Espanhol monjo/monja, Alemão Mönch e Inglês monk) para monaho, bego (muitas línguas com sonoridade similar a begin/begard) para begino/begardo.

\section{TRANSIR-FACILIGA PARENTISMO}

São as raízes do transir-faciliga parentismo (parentismo de facilitação da transição), as mesmas que a do internacieca parentismo, exceto as seguintes: fizo (do Sardenho fiza/fizu e Francês fille/fils), em vez de anako, para filo, ontio (do Inglês auntie, Francês oncle, Alemão Onkel, Esperanto oĉjo/onjo, Espanhol tío/tía, Português tio/tia), em vez de ĉaĉ, para onklo, rejĝ (do J-sistemo, rejĝg), em vez de rojalo, para reğo, grofo (do Croato, Sérvio, Esloveno e Romeno grof, do Húngaro e Eslovaco gróf, do Russo graf, do Alemão Graf), em vez de komto, para grafo.

\section{CONCLUSÃO}

O presente artigo mostrou como se deram, no entorno da comunidade de gramática prescritiva da variante padrão adloquial do Esperanto, discussões acerca de como estabelecer a transição para uma variante neutra de gênero, a partir de diferentes doutrinas de interpretação do Fundamento e de considerações sincrônico-diacrônicas acerca da relação entre Esperanto e gênero, de modo a produzir sistemas completos de gramática prescritiva, com uso efetivo por comunidades linguísticas.

Cumpre observar que, embora pareça, que tais discussões e prescrições de variantes sejam mais trabalhos individuais ou de pequenos grupos, há uma intensa discussão na comunidade esperantófona, bem como na comunidade de prescrição, em grupos de esperantologia, por trás de cada variante.

A fim de complementar os estudos que fiz para a minha apresentação no Simpósio de Esperantologia, creio pertinente incluir um comentário sobre uma pesquisa estatística sobre o efetivo uso de pronomes neutros em Esperanto, chamada La efektiva uzado de seksneŭtralaj pronomoj laŭ empiria esplorstudo (o efetivo uso de pronomes neutros de acordo com estudo empírico), de autoria de KRAMER (2020). Para fazê-lo, far-se-á necessário estudar outras variantes de linguagem neutra em Esperanto, desta vez não ligadas à questão das raízes (aqui já abordada), mas antes da questão pronominal.

Quanto ao uso de um pronome neutro, as vertentes mais comuns são o riismo, o 
giismo, o riismo radical, o giismo radical, o uso de tiu e o uso tradicional de $l i$.

O riismo corresponde ao uso do pronome $r i$ - proposto pela primeira vez por Ole Hageman em 1979 na revista Sekso kaj Egaleco (Sexo e Igualdade) conforme artigo da Wikipédia em Esperanto - para alusão a pessoas de gênero não especificado, no ato de fala, e para aludir às pessoas não binárias cujo pronome seja ri.

O giiismo corresponde ao uso do pronome $\hat{g} i$, resgantando o uso dele para falar de crianças (ou seja, referir-se a seres humanos, rompendo com a forte distinção ajo/ulo tradicional e também presente em boa parte das variantes de gênero neutro do Esperanto), para alusão a pessoas de gênero não especificado, no ato de fala e também como pronome usado por pessoas não binárias.

O riismo radical, por sua vez, trata do uso do pronome ri também como um movimento de substituição dos pronomes pessoais li e $\hat{s} i$ pelo pronome ri. Já o giiismo radical, por sua vez, trata também do uso do pronome neutro como um movimento de substituição dos pronomes pessoais $l i$ e $\hat{s} i$, porém, com o pronome $\hat{g} i$, em vez de $r i$.

Além deles, há o uso do pronome demonstrativo correlativo tiu, usado sozinho, por alusão a uma locução substantiva cujo núcleo passou por elisão. Além disso, há o uso tradicional de $l i$ com essa função (de modo que a distinção ajo/ulo entre $l i$ e $\hat{g} i$ é fortalecida) e na contramão do sentido contemporâneo de $l i$.

Assim, surgem movimentos que buscam preencher a lacuna lexical e semântica gerada por essa ressignificação de $l i$ comparativamente a seu sentido contemporâneo, dentre quais movimentos pode-se citar o do uso do neopronome (neologismo pronominal) $h i$ substituindo $l i$. É comum se usar, dando a li seu uso contemporâneo, a forma li kaj $\hat{s} i$ ou $l i$ a $\breve{u} \hat{s} i$, a partir do uso de $k a j$ (e) e de $a \breve{u}$ (ou). Além disso, além de ri e de ĝi (que em certo sentido em seu uso proposto acaba se configurando, em certa medida, como um neopronome), há, ainda, também outro neopronome, ŝli.

Kramer, neste artigo, mostra os resultados de sua pesquisa empírica estatística sociolinguística. A fim de definir melhor sua amostragem, devido à possibilidade de contaminação da mesma, ou de enviesamento, na medida em que pessoas que não representariam um uso linguístico fluente do Esperanto, mas apenas estudantes no início de sua aprendizagem, Kramer estabelece um questionário com graus diferente de pontuação conforme a dificuldade da pergunta em relação à variante padrão do Esperanto. Retirou-se quem não atingiu uma pontuação mínima no questionário.

Os resultados mostram que $r i$, com $81 \%$ da amostra, já é um neopronome amplamente conhecido. O uso de ri como neopronome para pessoas não binárias é a maneira mais popular de se referir a pessoas não binárias, correspondendo ao uso 
linguístico de $38 \%$ da amostragem, contrastando com $10 \%$ da amostragem, ao qual corresponde o uso linguístico de $\hat{g} i$ para alusão a pessoas não binárias.

É pertinente observar, aqui, uma importante distinção entre alusão genérica a alguém pertencente a um grupo, e alusão específica a um indivíduo que pertença a este grupo. Clarificarei tal distinção em sua aplicação à questão neopronominal. Referir-se a alguém como pertencente ao grupo de pessoas não binárias por um dado pronome (que marcará tal pertencimento em seu campo semântico) é um fenômeno distinto da alusão específica a um indivíduo não binário. No segundo caso, o pronome dele ser respeitado é uma prática extremamente comum nos círculos de variantes de gênero neutra. Todavia, na alusão genérica a uma pessoa não binária, o pronome preferido pessoal não é pertinente, uma vez que se está numa esfera genérica de alusão a um indivíduo qualquer genérico pertencente ao grupo de pessoas não binárias.

Além disso, uma vez que esta pesquisa empírica trata não de comunidades linguísticas de linguagem neutra, mas, antes, da comunidade esperantófona fluente de modo geral, então, a peculiar maneira de compreender gênero e linguagem não será a da comunidade de linguagem neutra, mas sim a da esperantofonia como um todo. Assim, não obstante em tal comunidade, pronomes não sejam vistos como marcando gênero, e sim como sendo uma categoria gramatical historicamente ligada ao gênero mas que encontra-se sob o universo da expressão de gênero, numa consideração mais rigorosa, em consonância com a prática do pronome preferido pessoal como atinente à autodeterminação do sujeito político e linguístico referido por tais pronomes. Todavia, vale lembrar, esta não é a compreensão majoritária da esperantofonia.

Os resultados dispostos no artigo também mostram que, no caso de alusão sem marcação de gênero (como no caso da alusão genérica a um alguém qualquer), não há variação significativa na quantidade percentual da amostragem correspondente a cada comunidade linguística.

Além disso, o riismo radical, correspondendo a $6,7 \%$ e o giismo radical, correspondente a $3,4 \%$ da amostragem, não representam um uso linguístico significativo dentro da comunidade linguística esperantófona.

Outro resultado obtido nesta pesquisa empírica foi a variação linguística diastrática. Dentre jovens esperantistas, sobretudo com menos de 30 anos, a compreensão do neopronome ri, o uso de ri por pessoas não binárias, o uso de ri para uma alusão genérica a alguém sem marcação de gênero e o riismo radical são usos linguísticos significativamente mais expressivos e consolidados comparativamente a esperantistas com mais de 60 anos. Isto aponta na direção de que, com o passar do tempo devido 
ao surgimento de novas gerações, o envelhecimento de gerações jovens e o gradativo falecimento de gerações idosas, dê-se a formação também de uma variação linguística diacrônica da variação padrão do Esperanto então vigente, e futuro relativamente a nosso momento histórico, comparativamente à variação padral do Esperanto hoje vigente. 


\section{REFERÊNCIAS:}

BORSCH, Kiril. Seksa egaligo en la lingvo laŭfundamente. 2015. Disponível em: $<$ https://lingvakritiko.com/2015/01/31/seksa-egaligo-en-la-lingvo-laufundamente/>. Acesso em 25 nov. 2019.

INO. In: SENNACIECA ASOCIO TUTMONDA. Plena Ilustrita Vortaro 2020. 2020. Disponível em: $<$ https://vortaro.net/\#ino_kd>. Acesso em 26 ago. 2020.

KALOCSAY, Kálman. WARIGHIEN, Gaston. Plena Analiza Gramatiko de Esperanto. 1987. Disponível em: <http://luisguillermo.com/PAG/Plena_Analiza_Gramatiko_(K._ Kalocsay,_G._Waringhien).pdf $>$. Acesso em 26 ago. 2020.

KRAMER, Markos. BORSCH, Kirilo. CERANTE, Luko. VLIET, Robin van der. Survoje al sekse neŭtralaj kaj egalecaj esprimoj: Komparo inter la j-sistemo kaj parentismo. 2019. Disponível em: <https://ingvakritiko.com/2019/11/11/survoje-alsekse-neutralaj-kaj-egalecaj-esprimoj-komparo-inter-la-j-sistemo-kaj-parentismo/>. Acesso em 25 nov. 2019.

KRAMER, Marcos. Esperanto kaj sekso. 2014. Disponível em: < https://lingvakritiko. com/2014/10/16/esperanto-kaj-sekso/>. Acesso em 25 nov. 2019.

KRAMER, Markos. La efektiva uzado de seksneŭtralaj pronomoj laŭ empiria esplorstudo. 2020. Disponível em: <https://lingvakritiko.com/2020/05/12/la-efektiva-uzado-deseksneutralaj-pronomoj-lau-empiria-esplorstudo/>. Acesso em 3 jul. 2020.

SEKSO. In: SENNACIECA ASOCIO TUTMONDA. Plena Ilustrita Vortaro 2020. 2020. Disponível em: <https://vortaro.net/\#sekso_kd>. Acesso em: 26 agosto 2020.

WENNERGREN, Bertilo. Plena Manlibro de Esperanta Gramatiko. 2020. Disponível em: <https://bertilow.com/pmeg/>. Acesso em 26 ago. 2020.

RIISMO In:WIKIMEDIA FOUNDATION. Vikipedio, la Libera Enciklopedio. 2020. Disponível em: <https://eo.wikipedia.org/wiki/Riismo>. Acesso em 3 jul. 2020. 